\title{
Effect of ripeness and postharvest storage on the evolution of colour and anthocyanins in cherries (Prunus avium L.)
}

\author{
Berta Gonçalves a , Ana Paula Silva ${ }^{\mathrm{b}}$, José Moutinho-Pereira ${ }^{\mathrm{a}}$, Eunice Bacelar ${ }^{\mathrm{a}}$, \\ Eduardo Rosa b, Anne S. Meyer ${ }^{\mathrm{c}, *}$ \\ a CETAV-Centre for Technological, Environmental and Life Studies, Department of Biological and Environmental Engineering, \\ University of Trás-os-Montes e Alto Douro, Apartado 1013, 5000 Vila Real, Portugal \\ ${ }^{\mathrm{b}}$ CECEA - Research Centre for Agricultural Sciences and Engineering, Department of Plant Science and Agricultural Engineering, \\ University of Trás-os-Montes e Alto Douro, Apartado 1013, 5000 Vila Real, Portugal \\ c BioProcess Engineering, Department of Chemical Engineering, Building 229, Technical University of Denmark, 2800 Lyngby, Denmark
}

Received 17 January 2005; received in revised form 17 August 2006; accepted 17 August 2006

\begin{abstract}
The relationship between colour parameters and anthocyanins of four sweet cherry cultivars, Burlat, Saco, Summit and Van was studied. The colour $\left(L^{*}, a^{*}, b^{*}\right.$, chroma and hue angle parameters) and anthocyanins were analysed during two different years at two different ripening stages (partially ripe, and ripe, respectively). The cherries were analysed at harvest and after storage at $1.5 \pm 0.5^{\circ} \mathrm{C}$ and $15 \pm 5^{\circ} \mathrm{C}$ for 30 and 6 days, respectively. The colour was measured by tristimulus colourimetry (CIELAB system) directly on the fruits, while anthocyanins were quantified by HPLC-DAD analysis on methanolic extracts of freeze-dried samples of the fresh cherries and on the differently stored cherries. $L^{*}$, chroma, and hue angle values were always lower for the ripe than for the partially ripe cherries. All of the cultivars were found to contain cyanidin-3-rutinoside and cyanidin-3-glucoside as the major anthocyanins. The total anthocyanin content in fruits of the different cultivars varied in the order Burlat $>$ Saco $>$ Van $>$ Summit. The concentration of anthocyanins increased at both temperatures of storage in both ripe and partially ripe cherries, but the extent of increase varied among cultivars. Cherries stored at $15 \pm 5{ }^{\circ} \mathrm{C}$ showed higher reduction of $L^{*}$, chroma and hue angle than fruits stored at $1.5 \pm 0.5^{\circ} \mathrm{C}$. $L^{*}, a^{*}, b^{*}$, chroma and hue angle correlated negatively $(P<0.001)$ with the total anthocyanins levels, but not with the total phenols. These results show that chromatic functions of chroma and hue correlate closely with the evolution of colour and anthocyanins levels during storage of sweet cherries and indicate that colour measurements can be used to monitor pigment evolution and anthocyanin contents of cherries (and vice versa).
\end{abstract}

(C) 2006 Elsevier Ltd. All rights reserved.

Keywords: Anthocyanins; Cherries; Chromatic coordinates; Chroma; Colour evolution; Hue angle; Ripeness stage; Storage

\section{Introduction}

Colour is one of the most important indicators of maturity and quality of fresh, stored, and processed cherries (Drake, Proebsting, \& Spayd, 1982). In cherries, colour is mainly influenced by the concentration and distribution of different anthocyanins in the skin (Gao \& Mazza, $1995)$ as well as $\mathrm{pH}$ and levels and types of colourless phen-

\footnotetext{
${ }^{*}$ Corresponding author. Tel.: +45 45252600; fax: +4545884922.

E-mail address: am@kt.dtu.dk (A.S. Meyer).
}

olics in the fruits and other factors such as light, temperature, oxygen, metal ions and enzymes (Delgado-Vargas \& Paredes-López, 2003).

In a previous study we showed that levels of anthocyanins in four sweet cherry cultivars, Burlat, Saco, Summit and Van, ranged from $\sim 5$ to $86 \mathrm{mg} / 100 \mathrm{~g}$ of fresh weight (fw) in 2001, and from $\sim 6$ to $230 \mathrm{mg} / 100 \mathrm{~g}$ of $\mathrm{fw}$ in 2002 (Gonçalves et al., 2004). In general, the total anthocyanins levels were higher in 2002 than in 2001, but the profiles of anthocyanins were similar both among the two years and among all four cultivars (Gonçalves et al., 2004). The 


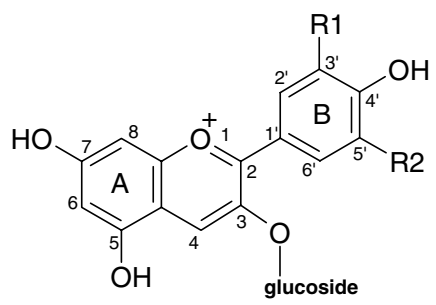

\begin{tabular}{lllll}
\hline $\mathrm{R}_{1}$ & $\mathrm{R}_{2}$ & Anthocyanin & Glucoside & Colour \\
\hline $\mathrm{H}$ & $\mathrm{H}$ & Pelargonidin & rutinoside & Red \\
$\mathrm{OH}$ & $\mathrm{H}$ & Cyanidin & glucoside & Orange-red \\
$\mathrm{OH}$ & $\mathrm{H}$ & Cyanidin & rutinoside & Red-purple \\
$\mathrm{OCH}_{3}$ & $\mathrm{H}$ & Peonidin & glucoside & Orange-red \\
$\mathrm{OCH}_{3}$ & $\mathrm{H}$ & Peonidin & rutinoside & Orange-red \\
\hline
\end{tabular}

Fig. 1. The basic chemical structure of the six most commonly occurring anthocyanins in sweet cherries. The structures shown the hydroxylation and methoxylation substitution pattern, type of glycosidic residue, and colour of the flavylium ion form (prevailing at acidic $\mathrm{pH}$ ).

major anthocyanins in sweet cherries include the 3-O-glucoside and 3-O-rutinoside (-rhamnosyl-D-glucopyranose) of cyanidin, with peonidin-3-O-rutinoside and -glucoside, as well as pelargonidin-3-O-rutinoside occurring in much lower amounts (Fig. 1) (Esti, Cinquanta, Sinesio, Moneta, \& Di Matteo, 2002; Gao \& Mazza, 1995; Gonçalves et al., 2004). Gao and Mazza (1995) reported that the total anthocyanin content ranged from 82 to $297 \mathrm{mg} / 100 \mathrm{~g}$ for dark cherries and from 2 to $41 \mathrm{mg} / 100 \mathrm{~g}$ for the light coloured cherries. The cyanidin-3-rutinoside and the cyanidin-3-glucoside contents in pitted, sweet cherry cultivars have been found to range from 4 to $44 \mathrm{mg} / 100 \mathrm{~g}$ of $\mathrm{fw}$ and from 2 to $243 \mathrm{mg} / 100 \mathrm{~g}$ of fw, respectively (Gao \& Mazza, 1995).

As expected, the total levels of anthocyanins are higher in ripe cherries than in partially ripe ones (Gonçalves et al., 2004). In freshly harvested, fully ripe cherries, the levels of cyanidin-3-rutinoside were in our previous study found to represent $63-94 \%$ by weight of the total anthocyanins. In both years, cherries of cv. Burlat showed the highest anthocyanin levels, particularly with respect to the cyanidin-3glucoside levels. The levels of anthocyanins increased during storage, and after storage the total anthocyanins represented around $50 \%$ of total phenolics. The cherries from cv. Van exhibited the most profound increase in total anthocyanin levels during storage, and the increase in total anthocyanin levels was mainly attributable to increases in the cyanidin-3-rutinoside level (Gonçalves et al., 2004). Studies for anthocyanin levels in mature grapes stored at $0{ }^{\circ} \mathrm{C}$ supported our findings, since a slight increase, from 4500 to $6000 \mathrm{mg} / \mathrm{kg}$ of peel $\mathrm{fw}$, was shown previously for these compounds (Cantos, García-Viguera, Pascual-Teresa, \& Tomás-Barberán, 2000).

The colorimetric CIE system, Commission International d'Eclairage, is widely used in the quantification and characterization of anthocyanin chromatic properties and in the assessment of colour quality and colour changes during maturity and processing of plant foods (Dodds, Brown,
\& Ludford, 1991; Heredia, Francia-Aricha, Rivas-Gonzalo, Vicario, \& Santos-Buelga, 1998).

Fresh sweet cherries represent an important, but fragile, commodity in the Portuguese agricultural export market. The harvesting season is very short, and cold storage is used to stretch the supply period in the season. However, the effects of different storage conditions on cherry quality, including colour development, is not well studied and the available knowledge on anthocyanins levels versus colour development during cherry storage appears somewhat confusing. In a study of two sweet Italian cherry cultivars, Sciazza and Ferrovia, it was found that the content of cyanidin-3-rutinoside and cyanidin-3-glucoside in the cherries decreased several fold during cold storage for 15 days at $1{ }^{\circ} \mathrm{C}$ (Esti et al., 2002). Nevertheless, the colour attributes of the same cherries, measured as CIE: $L^{*}, a^{*}$, and $b^{*}$ values of the cherry skins and pulp, did not change significantly during storage independent of the storage temperature - the only exception being a decrease in $L^{*}$ observed for the skin of the cv. Ferrovia cherries (Esti et al., 2002). In contrast, as discussed above, we previously observed increases in anthocyanin levels during storage suggesting that colour attributes would change during storage (Gonçalves et al., 2004). This study was therefore undertaken to: (a) determine the evolution of colour in sweet cherries during postharvest storage at different temperatures, (b) assess the relationship between colour attributes and anthocyanins content in cherries, and (c) unravel any potential differences in colour attributes and anthocyanin-colour relationships among four different cherry cultivars.

\section{Materials and methods}

\subsection{Cherry raw material}

Four sweet cherry cultivars, Burlat, Saco, Summit and Van from an orchard in Vila Real, Portugal, were randomly hand harvested in 2001 and 2002, both years as partially ripe and ripe. The fruit analyses were made at harvest and during storage at typical, industrially used fruit storage conditions, that is at $1.5 \pm 0.5^{\circ} \mathrm{C}$ and $90 \% \mathrm{RH}$ (cool temperature) for 30 days or at $15 \pm 5{ }^{\circ} \mathrm{C}$ (room temperature) for 6 days. The details on the quality criteria decisive for picking as well as an elaborate examination of the evolution of quality parameters in the four different cherry cultivars during storage (in addition to effects of maturity stage at picking) have been reported separately (Gonçalves et al., 2004).

\subsection{Colour analyses}

Ground colour was measured on 20 fruits using a tristimulus colorimeter (Minolta CR-200B Chroma Meter, Minolta, Japan) having an $8 \mathrm{~mm}$ diameter viewing area. Chromatic analyses were carried out following the CIE (Commission International de l'Eclairage) system of 1976. 
Values of $L^{*}, a^{*}$ and $b^{*}$ were measured to describe a threedimensional colour space and interpreted as follows: $L^{*}$ indicates lightness read from 0 (completely opaque or "black") to 100 (completely transparent or "white"). A positive $a^{*}$ value indicates redness $\left(-a^{*}\right.$ is greenness) and a positive $b^{*}$ value yellowness $\left(-b^{*}\right.$ is blueness) on the hue-circle (Hutchings, 1994; Voss, 1992). The hue angle $\left({ }^{\circ}\right)$, hue $=\operatorname{arctg}\left(b^{*} / a^{*}\right)$, expresses the colour nuance (Voss, $1992)$ and values are defined as follows: red-purple: $0^{\circ}$, yellow: $90^{\circ}$, bluish-green: $180^{\circ}$, and blue: $270^{\circ}$ (McGuire, 1992). The chroma, obtained as $\left(a^{* 2}+b^{* 2}\right)^{1 / 2}$, is measure of chromaticity $\left(C^{*}\right)$, which denotes the purity or saturation of the colour (Voss, 1992). The data of each measurement are the average of triplicate measures on equidistant points of each fruit.

\subsection{Chemicals and reagents}

Anthocyanin-glucosides were purchased from Polyphenols A/S (Stavanger, Norway) and the HPLC grade acetonitrile was purchased from Merck (Darmstadt, Germany).

\subsection{Extraction of anthocyanins}

Pitted and freeze-dried cherry samples $(0.5 \mathrm{~g})$ were contacted with $60 \% \mathrm{v} / \mathrm{v}$ aqueous $\mathrm{MeOH}(5 \mathrm{ml})$; flushed with $\mathrm{N}_{2}$, and extracted for $10 \mathrm{~min}$ using a shaking (200 rpm) water bath at $25^{\circ} \mathrm{C}$. The individual samples were then filtered through one layer of Whatman No. 1 filter paper (using vacuum suction during the filtration) and the solvent contacting was repeated twice on the residue. Each filtrate was then filtered through a $0.45 \mu \mathrm{m}$ syringe-tip hydrophilic Durapore filter (Millipore Corp., Bedford, MA) prior to high performance liquid chromatography (HPLC) analyses. The reported values are the sums of the values obtained from each extraction and each HPLC analysis.

\subsection{Anthocyanins and phenols analyses}

HPLC analysis was carried out according to the procedure described by Lamuela-Raventós and Waterhouse (1994) using a Hewlett-Packard 1100 system (Waldbronn, Germany) equipped with a diode array detector (DAD), a Nova-Pak C18 column $(3.9 \times 150 \mathrm{~mm}$, Waters $)$ at $40^{\circ} \mathrm{C}$, and controlled by a PC with HPChem station Software. The solvent flow rate was $0.5 \mathrm{ml} / \mathrm{min}$ and the injected volume was $10 \mu \mathrm{l}$. The anthocyanins were identified by spectral and retention time analysis. The quantities of the different phenolic compounds were assessed from peak areas and calculated as equivalents of standard compounds from linear regression curves of authentic standards. The anthocyanins were quantified at $520 \mathrm{~nm}$, in $\mathrm{mg} / 100 \mathrm{~g}$ of $\mathrm{fw}$, as cyanidin-3-glucoside and cyanidin-3-rutinoside, respectively, while the quantities of peonidin-3-glucoside, peonidin-3-rutinoside, and pelargonidin-3-rutinoside were calculated as cyanidin-3-rutinoside equivalents.

\subsection{Statistics}

Analyses of variance were accomplished by use of the Super ANOVA software (1.11 Abacus Concepts Inc., 1991). Significances of differences were established from a Duncan's Test $(P<0.05)$. A Fisher correlation analysis including all the parameters was also performed. Possible differences between cultivars in the correlation between two parameters were analyzed by comparison of regression lines.

\section{Results and discussion}

\subsection{HPLC-DAD analysis of cherry anthocyanins}

The HPLC chromatograms of sweet cherry extracts obtained in the visible spectral region $(520 \mathrm{~nm})$ revealed five peaks, which corresponded to five anthocyanins (Fig. 2): cyanidin-3-glucoside (peak 1), cyanidin-3-rutinoside (peak 2), peonidin-3-glucoside (peak 3), pelargonidin-3-rutinoside (peak 4) and peonidin-3-rutinoside (peak 5). As discussed below these findings are in complete agreement with what has been reported previously on anthocyanins in sweet cherries (Gao \& Mazza, 1995). The details on the evolution of anthocyanins in the four different cherry cultivars during storage (in addition to effects of maturity stage at picking and year) have been reported separately (Gonçalves et al., 2004).

\subsection{Effect of ripeness and storage temperature on cherry colour}

The chromatic characteristics of the fruits studied are shown in Tables 1 and 2. There were significant differences in $L^{*}$, chroma and hue angle $(P<0.001)$ between the four cultivars, ripeness stage, year and storage. At harvest, Burlat cherries always showed lower hue angle and $L^{*}$ and higher anthocyanin levels in both years, a synonym of redder and darker cherries. Summit fruits showed higher $L^{*}$ and chroma, which is in accordance with the observation that Summit fruits are both less red and lighter in colour than the other cherry cultivars. $L^{*}$, chroma and hue angle of partially ripe cherries were always higher than in the ripe cherries, which means a less red fruit, and was correlated with lower anthocyanin content (Tables 1-3; Gonçalves et al., 2004).

$L^{*}$, chroma and hue angle of ripe and partially ripe cherries were always higher in 2001 (Tables 1 and 2). These parameters decreased during storage, mostly at room temperature, but the extent of change varied among the cultivars (Tables 1 and 2). In general, at $15 \pm 5{ }^{\circ} \mathrm{C}$, chroma was the parameter that showed higher reduction in 2001 and 2002 (Tables 1 and 2). The decrease in chroma means an increase in the tonality of the fruit colour. A reduction of 19 units was measured in Van cherries in 2001 (Table 1). Rodríguez-Saona, Giusti, and Wrolstad (1999) observed a reduction of 10 units in chroma, in radish-coloured juices 

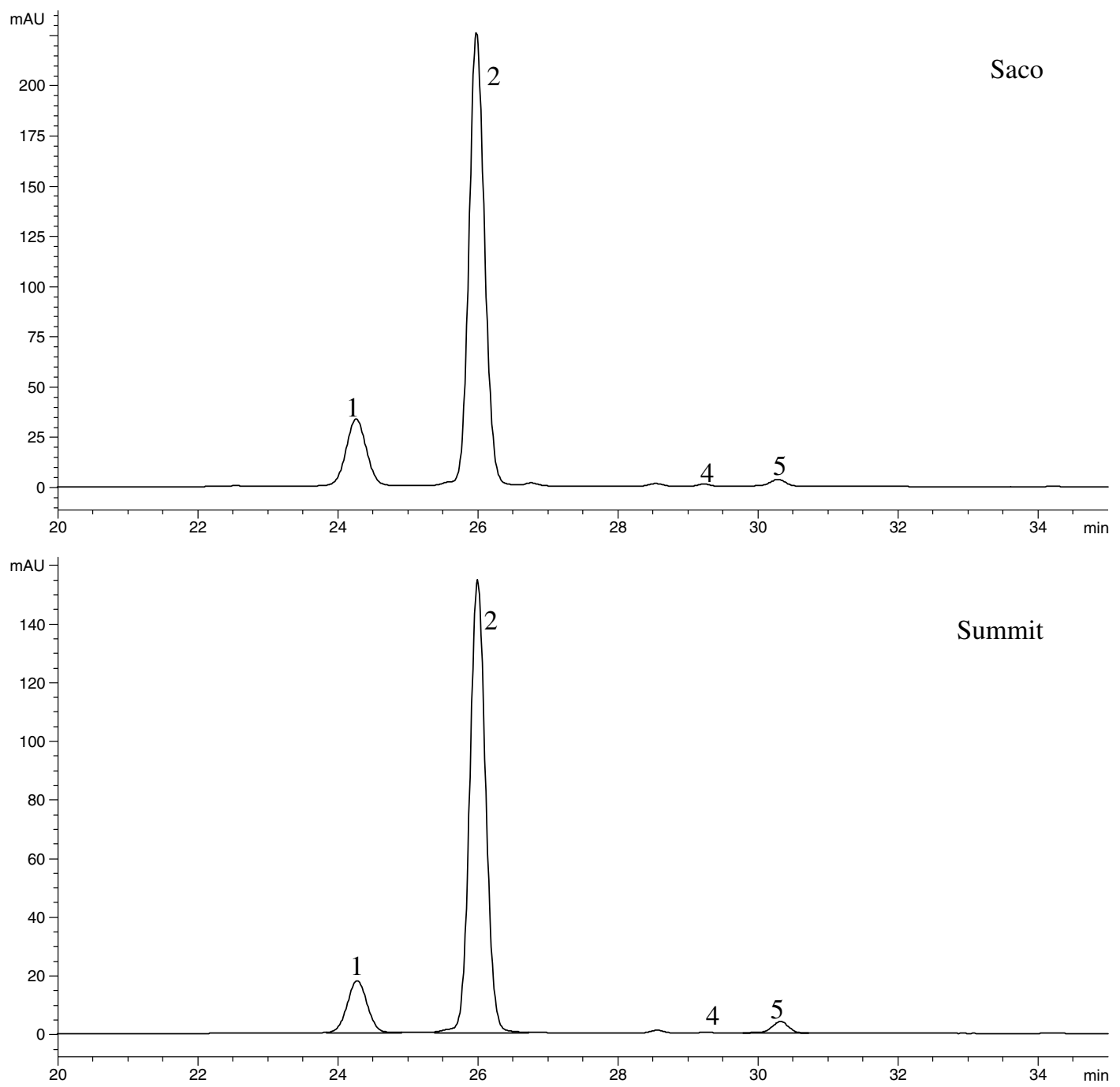

Fig. 2. HPLC separation of anthocyanins in a methanolic extract of the four sweet cherry cultivars, monitored at $520 \mathrm{~nm}$. Peaks: 1, cyanidin-3-glucoside; 2, cyanidin-3-rutinoside; 3 , peonidin-3-glucoside; 4, pelargonidin-3-rutinoside; 5 , peonidin-3-rutinoside.

after storage at 16 days at $25^{\circ} \mathrm{C}$. A decrease in chroma during fruit storage was also observed with stored strawberries (Abers \& Wrolstad, 1979). The decrease could have been caused by an increase in total anthocyanins and a decrease in chlorophyll and carotenoids, and, according to Abers and Wrolstad (1979), by development of dark, pigmented compounds, which tend to mask colour.

All treatments induced a reduction in hue angle values, when compared to the values observed at harvest (Tables 1 and 2). The loss of lightness was reflected by a reduction of $L^{*}$ (the photometric parameter proportional to the light reflected by the object) and was directly related to the humidity during storage (humidity data not shown). Hence, the cherries of all four cultivars became a little darker as well as a little redder during storage, as shown by decreases in $L^{*}$ values and in hue angle values (Tables 1 and 2), during both the cool $\left(1.5^{\circ} \mathrm{C}\right)$ and the ambient $\left(15^{\circ} \mathrm{C}\right)$ storage periods. However, the changes in colorimetric parameters varied depending on the storage temperature and the anthocyanins composition in the different cherry cultivars. Refrigerated temperatures greatly improved the colour stability of the cherries. Differences in hue angle could be attributed to both differences in anthocyanin and phenols composition, and to interaction of anthocyanins with other compounds at the relatively low $\mathrm{pH}$ of the fruits (intermolecular co-pigmentation). Co-pigmentation is optimal in the range $\mathrm{pH} 3-5$ (Brouillard, Wingand, Dangles, \& Cheminal, 1991), and is known to decrease with increasing temperature (Baranac, Petranović, \& Dimitrić-Marković, 1996). In addition, the low $\mathrm{pH}$ increases the stability of anthocyanins (Eiro \& Heinonen, 2002). On this basis we ascribe the fact that cherries can be stored for at least one month at $1.5^{\circ} \mathrm{C}$ without degradation of anthocyanins to be due to stabilization by $\mathrm{pH}$ and co-pigmentation. However, to firmly establish the mechanism behind the stabilization of the colour of the cherries during storage, further chemical analyses including LC-MS and NMR analyses are warranted. 

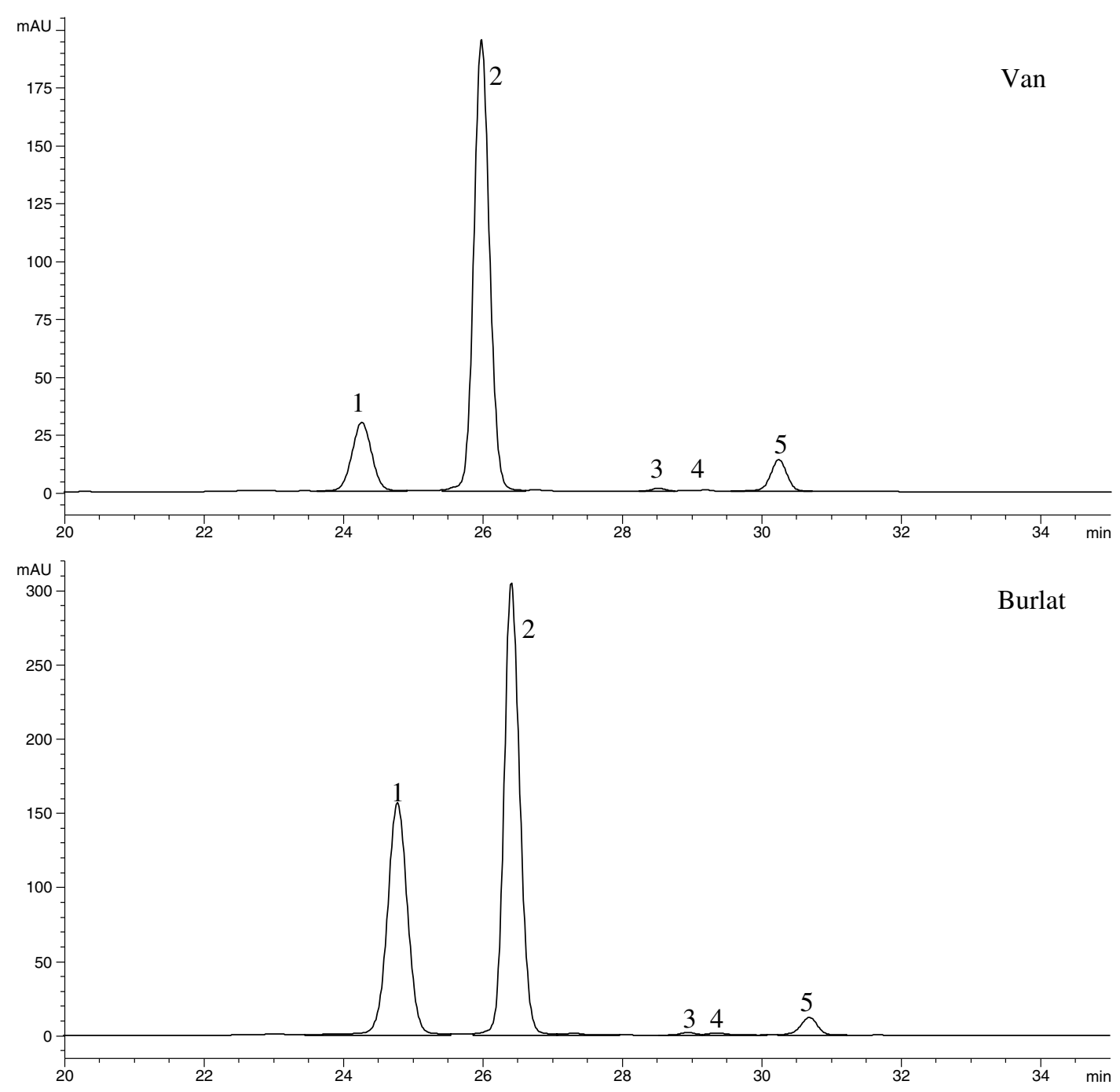

Fig. 2 (continued)

\subsection{Influence of $p H$ on cherry colour}

The decrease in chromatic parameters was associated with a weak increase in the $\mathrm{pH}$ (Tables 1 and 2; Gonçalves et al., 2004). The same results were observed by Heredia et al. (1998), who found that the chroma defined in the uniform colour spaces, underwent a linear decrease as $\mathrm{pH}$ increased. The influence of $\mathrm{pH}$ on fruit colour is well known. As $\mathrm{pH}$ increases, the colour of anthocyanins moves to the non-spectral purple and approaches a progressive loss of colour.

\subsection{Correlations and regressions between anthocyanins content and colour}

With all the cherry cultivars, the levels of anthocyanins correlated negatively with each of the colour parameters $L^{*}, a^{*}, b^{*}$, chroma and hue angle (Table 3 ). The steepest and most significant correlations were found for the cultivars having highest levels of anthocyanins, namely Burlat and Van (Table 3). The different correlation coefficients obtained for the different cherry cultivars means that the evolution of colour during storage varied among the different cherry cultivars. Some of the main aims of the present work were to assess the evolution of colour in relation to anthocyanin profiles in different cherry cultivars, and notably to unravel any differences in the anthocyanin-colour relationships among different cherry cultivars. For this reason the number of samples taken from each cultivar is not sufficient to build a valid mathematical function to robustly predict the colour evolution during storage of each different cultivar. Thus, for a more comprehensive mathematical function describing the colour development in individual cherry cultivars, collection of more data from a large number of samples is recommended. The next step in such studies will be to predict the colour evolution and select the optimal storage mode for individual cherry cultivars.

When lumping the data for all four cultivars, all the negative correlations obtained statistical significance. The chromatic parameters $L^{*}, a^{*}, b^{*}$, chroma and hue angle cor- 
Table 1

CIE $1976\left(L^{*} a^{*} b^{*}\right)$ colour space (CIELAB) of cherry cultivars at two ripeness stages (ripe and partially-ripe) and influenced by storage at $15 \pm 5{ }^{\circ} \mathrm{C}$ (room T) and $1.5 \pm 0.5^{\circ} \mathrm{C}(\operatorname{cool} \mathrm{T})$ for year 2001

\begin{tabular}{|c|c|c|c|c|c|c|}
\hline \multirow[t]{2}{*}{ Cultivar } & \multirow[t]{2}{*}{ Storage } & \multicolumn{3}{|c|}{ Chromatic coordinates } & \multirow[t]{2}{*}{ Chroma $C_{a b}^{*}$} & \multirow[t]{2}{*}{ Hue angle $h_{a b}$} \\
\hline & & $L^{*}$ & $a^{*}$ & $b^{*}$ & & \\
\hline \multicolumn{7}{|l|}{ Burlat } \\
\hline P-ripe & Day 0 & $51.80 \pm 7.09 \mathrm{j}$ & $36.43 \pm 6.76 \mathrm{def}$ & $21.17 \pm 2.34 \mathrm{hi}$ & $42.44 \pm 4.91 \mathrm{e}$ & $30.95 \pm 7.91 \mathrm{j}$ \\
\hline P-ripe & Cool T day 30 & $42.23 \pm 6.09 \mathrm{~h}$ & $37.00 \pm 3.38 \mathrm{efg}$ & $15.64 \pm 2.50 \mathrm{f}$ & $40.22 \pm 3.71 \mathrm{~d}$ & $22.85 \pm 2.86 \mathrm{de}$ \\
\hline Ripe & Day 0 & $37.34 \pm 4.75 \mathrm{de}$ & $36.15 \pm 5.89 \mathrm{def}$ & $15.45 \pm 4.41 \mathrm{f}$ & $39.36 \pm 7.09 \mathrm{~d}$ & $22.64 \pm 3.06 \mathrm{de}$ \\
\hline Ripe & Room T day 6 & $31.41 \pm 3.48 \mathrm{a}$ & $25.76 \pm 7.85 \mathrm{a}$ & $9.16 \pm 4.74 b c$ & $27.48 \pm 8.74 \mathrm{a}$ & $18.70 \pm 6.06 \mathrm{abc}$ \\
\hline Ripe & Cool T day 30 & $30.36 \pm 2.64 \mathrm{a}$ & $25.38 \pm 6.46 a$ & $7.78 \pm 3.40 \mathrm{a}$ & $26.59 \pm 7.15 \mathrm{a}$ & $16.32 \pm 3.15 \mathrm{a}$ \\
\hline \multicolumn{7}{|l|}{ Saco } \\
\hline P-ripe & Day 0 & $52.24 \pm 6.84 \mathrm{j}$ & $35.84 \pm 10.30 \mathrm{de}$ & $29.43 \pm 4.92 \mathrm{j}$ & $47.57 \pm 4.07 f$ & $40.48 \pm 13.47 \mathrm{k}$ \\
\hline P-ripe & Cool T day 30 & $41.25 \pm 5.59 \mathrm{gh}$ & $41.91 \pm 3.55 \mathrm{i}$ & $20.05 \pm 4.50 \mathrm{~h}$ & $46.60 \pm 4.44 f$ & $25.31 \pm 4.62 \mathrm{fg}$ \\
\hline Ripe & Day 0 & $38.52 \pm 2.66 \mathrm{ef}$ & $42.00 \pm 2.11 \mathrm{i}$ & $20.39 \pm 3.16 \mathrm{~h}$ & $47.57 \pm 4.07 \mathrm{f}$ & $25.75 \pm 2.85$ fgh \\
\hline Ripe & Room T day 6 & $30.20 \pm 1.34 \mathrm{a}$ & $31.25 \pm 3.21 b$ & $9.57 \pm 2.08 \mathrm{c}$ & $32.70 \pm 3.66 b$ & $16.84 \pm 1.93 \mathrm{ab}$ \\
\hline Ripe & Cool $\mathrm{T}$ day 30 & $33.23 \pm 3.09 b$ & $34.75 \pm 5.76 \mathrm{cde}$ & $12.32 \pm 3.90 \mathrm{~d}$ & $36.92 \pm 6.68 \mathrm{c}$ & $18.98 \pm 3.15 b c$ \\
\hline \multicolumn{7}{|l|}{ Summit } \\
\hline P-ripe & Day 0 & $55.27 \pm 7.10 \mathrm{k}$ & $34.19 \pm 10.23 \mathrm{~cd}$ & $29.20 \pm 3.53 \mathrm{j}$ & $45.98 \pm 4.77 \mathrm{f}$ & $41.76 \pm 12.97 \mathrm{k}$ \\
\hline P-ripe & Cool T day 30 & $46.43 \pm 5.75 \mathrm{i}$ & $38.34 \pm 4.51 \mathrm{fg}$ & $20.77 \pm 2.58 \mathrm{hi}$ & $43.82 \pm 2.83 \mathrm{e}$ & $28.76 \pm 6.00 \mathrm{ij}$ \\
\hline Ripe & Day 0 & $41.07 \pm 5.29 \mathrm{gh}$ & $38.54 \pm 3.01 \mathrm{fg}$ & $20.40 \pm 4.13 \mathrm{~h}$ & $43.73 \pm 3.83 \mathrm{e}$ & $27.71 \pm 4.41 \mathrm{ghi}$ \\
\hline Ripe & Room T day 6 & $35.39 \pm 2.05 \mathrm{c}$ & $37.01 \pm 3.30 \mathrm{efg}$ & $16.19 \pm 2.87 f$ & $40.43 \pm 4.10 \mathrm{~d}$ & $23.44 \pm 2.19 \mathrm{ef}$ \\
\hline Ripe & Cool T day 30 & $35.72 \pm 2.69 \mathrm{~cd}$ & $34.37 \pm 2.56 \mathrm{~cd}$ & $14.08 \pm 2.02 \mathrm{e}$ & $37.17 \pm 3.01 \mathrm{c}$ & $22.18 \pm 1.97 \mathrm{de}$ \\
\hline \multicolumn{7}{|l|}{ Van } \\
\hline P-ripe & Day 0 & $54.10 \pm 8.43 \mathrm{k}$ & $32.84 \pm 11.34 b c$ & $31.02 \pm 4.30 \mathrm{k}$ & $46.52 \pm 4.75 f$ & $44.79 \pm 14.52 \mathrm{e}$ \\
\hline P-ripe & Cool T day 30 & $39.42 \pm 5.21 \mathrm{fg}$ & $38.87 \pm 3.31 \mathrm{gh}$ & $18.68 \pm 4.29 \mathrm{~g}$ & $43.26 \pm 4.15 \mathrm{e}$ & $25.41 \pm 4.68 \mathrm{fg}$ \\
\hline Ripe & Day 0 & $41.56 \pm 4.15 \mathrm{~h}$ & $40.88 \pm 2.30 \mathrm{hi}$ & $21.81 \pm 2.96 \mathrm{i}$ & $46.41 \pm 2.74 f$ & $28.01 \pm 3.21 \mathrm{hi}$ \\
\hline Ripe & Room T day 6 & $29.93 \pm 1.38 \mathrm{a}$ & $26.49 \pm 4.40 \mathrm{a}$ & $8.11 \pm 2.27 \mathrm{ab}$ & $27.73 \pm 4.84 a$ & $16.73 \pm 2.19 \mathrm{ab}$ \\
\hline Ripe & Cool T day 30 & $33.17 \pm 2.61 b$ & $34.08 \pm 3.88 \mathrm{~cd}$ & $12.85 \pm 3.03 \mathrm{de}$ & $36.45 \pm 4.68 \mathrm{c}$ & $20.37 \pm 2.41 \mathrm{~cd}$ \\
\hline
\end{tabular}

Values are means $\pm \mathrm{SD}(n=60)$.

Means flanked by the same letter are not significantly different at $P<0.05$ (Duncan's test).

related negatively $(P<0.001)$ with the total anthocyanins levels, but not with total phenols $(P>0.05)$ (Table 4). In all cases, the lowest values of chroma and hue angle corresponded to the samples having the highest anthocyanins content. It seems logic that yellowness $\left(b^{*}\right)$ and lightness $\left(L^{*}\right)$, and consequently hue and chroma values may correlate negatively with the anthocyanins levels, but it is more complex to understand why an increase in pigments causing redness gives lower redness value readings, i.e. decreased $a^{*}$ values. This phenomenon was investigated and discussed in an early study on dark coloured fruit beverages by Eagerman, Clydesdale, and Francis (1973). They clearly demonstrated the presence of an "inversion area", where the increase anthocyanin pigment concentration, cyanidin-3-glucoside, where both the $L^{*}, a^{*}$ and $b^{*}$ values failed to correlate as expected to increases in the pigment concentration. In brief, this phenomenon is presumed to occur when increased pigment concentration both darkens the sample (e.g. the fruit or the fruit beverage) and increases the chroma. When this occurs, the colour scales are no longer tied linearly to the luminous transmittance (Eagerman et al., 1973). In our present work, the anthocyanins did indeed darken the cherries as their concentration increased, and therefore the chromaticity responses were no longer linear, and might, in fact, have reverted to correlate negatively. The darker the cherries, the more negative the correlation to anthocyanins levels. According to Little (1975) and McGuire (1992), hue angle and chroma give more information about spatial distribution of colours. Indeed, better correlation between these parameters and pigment concentrations have been obtained than when pigment concentrations were compared directly with the values from the colorimeter (McGuire, 1992).

For each relationship between total anthocyanins levels and chromatic parameters of the four sweet cherry cultivars, the regressions with highest determination coefficients and with significant $(P<0.05)$ regression coefficients were selected (Fig. 3). The best fit-adjustment (lower scattering) was found in the samples having less than $100 \mathrm{mg} / 100 \mathrm{~g}$ of fw of total anthocyanins.. This evidence suggested that the measure of chromatic parameters could be a good tool to predict the levels of anthocyanins in storage cherries and predict the beneficial human health effects of each sweet cherry cultivar, since anthocyanins exert antioxidant activity (Lapidot, Harel, Akiri, Granit, \& Kanner, 1999; Matsumoto, Nakamura, Hirayama, Yoshiki, \& Okubo, 2002; Wang et al., 1999). Therefore, for cherries for human consumption, it seems important to have a simple and non-destructive technique for anthocyanins content determination, and in this way easily and quickly assess and monitor cherry quality on a large number of cherries. 
Table 2

CIE $1976\left(L^{*} a^{*} b^{*}\right)$ colour space (CIELAB) of cherry cultivars at two ripeness stages (ripe and partially-ripe) and influenced by storage at $15 \pm 5{ }^{\circ} \mathrm{C}$ (room $\mathrm{T})$ and $1.5 \pm 0.5^{\circ} \mathrm{C}(\operatorname{cool} \mathrm{T})$ for year 2002

\begin{tabular}{|c|c|c|c|c|c|c|}
\hline \multirow[t]{2}{*}{ Cultivar } & \multirow[t]{2}{*}{ Storage } & \multicolumn{3}{|c|}{ Chromatic coordinates } & \multirow[t]{2}{*}{ Chroma $C_{a b}^{*}$} & \multirow[t]{2}{*}{ Hue angle $h_{a b}$} \\
\hline & & $L^{*}$ & $a^{*}$ & $b^{*}$ & & \\
\hline \multicolumn{7}{|l|}{ Burlat } \\
\hline P-ripe & Cool T day 30 & $38.13 \pm 4.43 \mathrm{~g}$ & $36.08 \pm 3.29 \mathrm{j}$ & $15.97 \pm 2.70 \mathrm{~g}$ & $39.49 \pm 3.97 \mathrm{k}$ & $23.72 \pm 2.29 \mathrm{gh}$ \\
\hline Ripe & Day 0 & $27.84 \pm 2.35 \mathrm{~cd}$ & $18.50 \pm 6.50 \mathrm{e}$ & $4.98 \pm 2.89 b c$ & $19.19 \pm 7.03 \mathrm{e}$ & $14.06 \pm 3.17 \mathrm{bcde}$ \\
\hline Ripe & Room T day 6 & $26.47 \pm 0.67 b c$ & $9.31 \pm 3.16 \mathrm{ab}$ & $1.98 \pm 0.82 \mathrm{a}$ & $9.52 \pm 3.25 \mathrm{ab}$ & $11.83 \pm 1.94 \mathrm{abc}$ \\
\hline Ripe & Cool $\mathrm{T}$ day 30 & $24.43 \pm 1.33 \mathrm{a}$ & $9.76 \pm 4.11 \mathrm{ab}$ & $2.44 \pm 1.25 \mathrm{a}$ & $11.43 \pm 11.04 \mathrm{~b}$ & $15.07 \pm 9.88 \mathrm{bcd}$ \\
\hline P-ripe & Day 0 & $46.94 \pm 8.14 \mathrm{i}$ & $36.27 \pm 7.80 \mathrm{j}$ & $24.73 \pm 6.15 j$ & $44.86 \pm 3.381$ & $34.76 \pm 12.51 \mathrm{k}$ \\
\hline P-ripe & Cool T day 30 & $29.80 \pm 2.94 \mathrm{de}$ & $32.08 \pm 4.89 \mathrm{i}$ & $10.74 \pm 3.47 \mathrm{e}$ & $33.87 \pm 5.74 \mathrm{i}$ & $18.05 \pm 2.91 \mathrm{f}$ \\
\hline Ripe & Day 0 & $30.53 \pm 2.73 \mathrm{e}$ & $26.59 \pm 6.56 \mathrm{~h}$ & $8.23 \pm 3.71 \mathrm{~d}$ & $27.90 \pm 7.31 \mathrm{~h}$ & $16.47 \pm 3.67 \mathrm{def}$ \\
\hline Ripe & Room T day 6 & $26.05 \pm 0.66 \mathrm{abc}$ & $12.16 \pm 2.94 \mathrm{~cd}$ & $2.21 \pm 0.79 \mathrm{a}$ & $12.36 \pm 3.03 \mathrm{~cd}$ & $10.10 \pm 1.32 \mathrm{a}$ \\
\hline Ripe & Cool T day 30 & $25.40 \pm 1.24 \mathrm{ab}$ & $13.57 \pm 3.91 \mathrm{~d}$ & $2.82 \pm 1.36 \mathrm{a}$ & $13.87 \pm 4.11 \mathrm{~d}$ & $11.25 \pm 2.19 \mathrm{ab}$ \\
\hline \multicolumn{7}{|l|}{ Summit } \\
\hline Ripe & Cool T day 30 & $27.93 \pm 2.55 \mathrm{~cd}$ & $23.72 \pm 5.48 \mathrm{~g}$ & $7.47 \pm 2.72 d$ & $24.90 \pm 6.01 \mathrm{~g}$ & $16.92 \pm 2.85 \mathrm{ef}$ \\
\hline \multicolumn{7}{|l|}{ Van } \\
\hline P-ripe & Day 0 & $59.14 \pm 8.41 \mathrm{j}$ & $23.36 \pm 12.90 \mathrm{fg}$ & $30.14 \pm 5.37 \mathrm{k}$ & $40.34 \pm 4.31 \mathrm{k}$ & $53.83 \pm 19.151$ \\
\hline P-ripe & Cool T day 30 & $39.35 \pm 14.30 \mathrm{~g}$ & $25.79 \pm 8.95 \mathrm{~h}$ & $16.65 \pm 10.51 \mathrm{gh}$ & $33.09 \pm 5.95 \mathrm{i}$ & $31.52 \pm 21.57 \mathrm{j}$ \\
\hline Ripe & Day 0 & $28.64 \pm 1.69 \mathrm{~d}$ & $21.53 \pm 5.41 f$ & $5.87 \pm 2.54 \mathrm{c}$ & $22.34 \pm 5.88 f$ & $14.57 \pm 2.83 \mathrm{cde}$ \\
\hline Ripe & Room T day 6 & $26.19 \pm 0.62 \mathrm{abc}$ & $7.79 \pm 2.53 \mathrm{a}$ & $1.42 \pm 0.48 \mathrm{a}$ & $7.93 \pm 2.57 \mathrm{a}$ & $10.50 \pm 1.92 \mathrm{a}$ \\
\hline Ripe & Cool T day 30 & $26.12 \pm 1.04 a b c$ & $10.71 \pm 3.52 b c$ & $2.33 \pm 0.90 \mathrm{a}$ & $10.96 \pm 3.62 b c$ & $12.17 \pm 1.81 \mathrm{abc}$ \\
\hline
\end{tabular}

Values are means $\pm \mathrm{SD}(n=60)$.

Means flanked by the same letter are not significantly different at $P<0.05$ (Duncan's test).

Table 3

Highlighting the different correlations between total anthocyanins and evolution of color parameters $\left(L^{*}, a^{*}, b^{*}\right)$ chroma $\left(C_{a b}^{*}\right)$ and hue angle $\left(h_{a b}\right)$ of ripe cherries during storage among cultivars

\begin{tabular}{|c|c|c|c|c|c|}
\hline & $L^{*}$ & $a^{*}$ & $b^{*}$ & $C_{a b}^{*}$ & $h_{a b}$ \\
\hline \multicolumn{6}{|l|}{ Total anthocyanins } \\
\hline Burlat & -0.739 & $-0.878^{*}$ & $-0.819^{*}$ & $-0.871^{*}$ & $-0.843^{*}$ \\
\hline Saco & -0.702 & -0.685 & -0.734 & -0.699 & -0.768 \\
\hline Summit & -0.675 & -0.721 & -0.733 & -0.729 & -0.774 \\
\hline Van & -0.665 & $-0.839^{*}$ & -0.727 & $-0.823^{*}$ & -0.744 \\
\hline Sum anthocyanins all cultivars & $-0.675^{* *}$ & $-0.791^{* * *}$ & $-0.729^{* * *}$ & $-0.784^{* * *}$ & $-0.745^{* * *}$ \\
\hline
\end{tabular}

* Indicates $P<0.05$.

** Indicates $P<0.01$.

*** Indicates $P<0.001$ by Fisher's test.

Table 4

Correlation matrix between anthocyanins (total and individual anthocyanins) and total phenols with chromatic coordinates $\left(L^{*}, a^{*}, b^{*}\right), \operatorname{chroma}\left(C_{a b}^{*}\right)$ and hue angle $\left(h_{a b}\right)$ of the four cherry cultivars during storage

\begin{tabular}{|c|c|c|c|c|c|}
\hline & $L^{*}$ & $a^{*}$ & $b^{*}$ & $C_{a b}^{*}$ & $h_{a b}$ \\
\hline Cyanidin-3-glucoside & $-0.548^{* * *}$ & $-0.709^{* * *}$ & $-0.629^{* * *}$ & $-0.729^{* * *}$ & $-0.548^{* * *}$ \\
\hline Cyanidin-3-rutinoside & $-0.710^{* * *}$ & $-0.779^{* * *}$ & $-0.772^{* * *}$ & $-0.831^{* * *}$ & $-0.702^{* * *}$ \\
\hline Peonidin-3-glucoside & $-0.449^{* *}$ & $-0.660^{* * *}$ & $-0.529^{* * *}$ & $-0.657^{* * *}$ & $-0.435^{* *}$ \\
\hline Pelargonidin-3-rutinoside & $-0.684^{* * *}$ & $-0.724^{* * *}$ & $-0.735^{* * *}$ & $-0.776^{* * *}$ & $-0.667^{* * *}$ \\
\hline Total anthocyanins & $-0.697^{* * *}$ & $-0.797^{* * *}$ & $-0.768^{* * *}$ & $-0.842^{* * *}$ & $-0.692^{* * *}$ \\
\hline Total phenols & $-0.533^{* * *}$ & $-0.408^{* *}$ & $-0.506^{* * *}$ & $-0.475^{* *}$ & $-0.520^{* * *}$ \\
\hline
\end{tabular}

\footnotetext{
${ }^{*}$ Indicates $P<0.05$.

** Indicates $P<0.01$.

${ }^{* * *}$ Indicates $P<0.001$ by Fisher's test.
} 


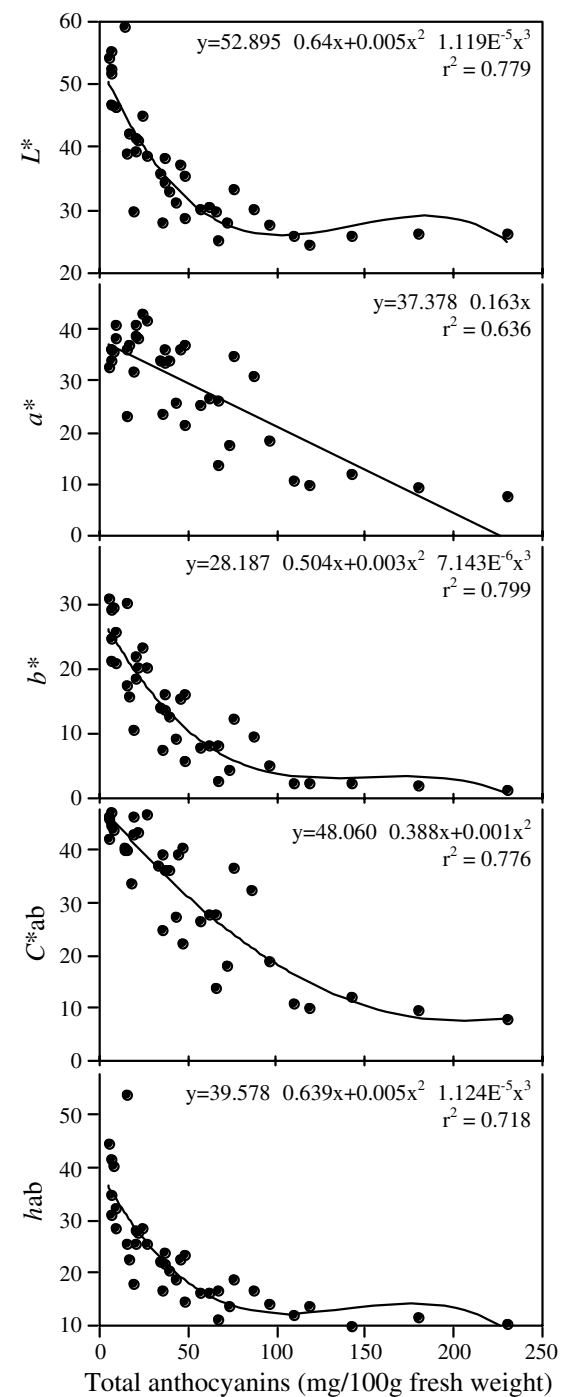

Fig. 3. Relationships between total anthocyanins and chromatic parameters of the four sweet cherry cultivar $(n=39)$. All the regression coefficients were significant $(P<0.05)$.

\section{Conclusions}

The chromatic parameters $L^{*}, a^{*}, b^{*}$, chroma and hue angle correlated negatively with the total anthocyanins levels, but not with the total phenols. In stored cherries the evolution of colour is a direct result of an increase in the levels of anthocyanins, particularly in the dominant anthocyanins cyanidin-3-rutinoside and -glucoside. Despite the variation on the anthocyanin levels in different cherry cultivars, which induces some variation in the degree of correlation between total anthocyanins and colour parameters, it is clear that colour measurements provide an easy assessment of the relative levels and changes of anthocyanins in different cherry cultivars during storage - and vice versa.

\section{Acknowledgements}

The authors are grateful to FCT - Project POCTI/ AGG/38146/2001, and Calouste Gulbenkian Foundation
Scholarship and the Socrates Programme supporting BG's visits to the Technical University of Denmark. We also thank Professor Alberto Santos for field management of the experimental orchard.

\section{References}

Abers, J. E., \& Wrolstad, R. E. (1979). Causative factors of colour deterioration in strawberry preserves during processing and storage. Journal of Food Science, 44(1), 75-81.

Baranac, J. V., Petranović, N. A., \& Dimitrić-Marković, J. M. (1996). Spectrophotometric study of anthocyan copigmentation reactions. Journal of Agricultural and Food Chemistry, 44, 1333-1336.

Brouillard, R., Wingand, M.-C., Dangles, O., \& Cheminal, A. (1991). pH and solvent effects on the copigmentation reaction of malvin with polyphenols, purine and pyrimidine derivatives. Journal of the Chemical Society, Perkin Transactions, 2, 1235-1241.

Cantos, E., García-Viguera, C., Pascual-Teresa, S., \& Tomás-Barberán, F. A. (2000). Effect of postharvest ultraviolet irradiation on resveratrol and other phenolics of $\mathrm{cv}$. Napoleon table grapes. Journal of Agricultural and Food Chemistry, 48, 4606-4612.

Delgado-Vargas, F., \& Paredes-López, O. (2003). Natural colorants for food and nutraceutical uses. Boca Raton, FL: CRC Press.

Dodds, G. T., Brown, J. W., \& Ludford, P. M. (1991). Surface colour changes of tomato and other solanaceous fruit during chilling. Journal of the American Society of Horticultural Science, 116(3), 482-490.

Drake, S. R., Proebsting, E. L., Jr., \& Spayd, S. E. (1982). Maturity index for the colour grade of canned dark sweet cherries. Journal of the American Society of Horticultural Science, 107, 180.

Eagerman, B. A., Clydesdale, F. M., \& Francis, F. J. (1973). Comparison of colour scales for dark coloured beverages. Journal of Food Science, $38,1051-1055$

Eiro, M. J., \& Heinonen, M. (2002). Anthocyanin colour behavior and stability during storage: effect of intermolecular copigmentation. Journal of Agricultural and Food Chemistry, 50, 7461-7466.

Esti, M., Cinquanta, L., Sinesio, F., Moneta, E., \& Di Matteo, M. (2002). Physicochemical and sensory fruit characteristics of two sweet cherry cultivars after cool storage. Food Chemistry, 76, 399-405.

Gao, L., \& Mazza, G. (1995). Characterization, quantification and distribution of anthocyanins and colourless phenolics in sweet cherry. Journal of Agricultural and Food Chemistry, 43, 343-346.

Gonçalves, B., Landbo, A.-K., Knudsen, D., Silva, A. P., MoutinhoPereira, J., Rosa, E., et al. (2004). Effect of ripeness and postharvest storage on the phenolic profiles of cherries (Prunus avium L.). Journal of Agricultural and Food Chemistry, 52(3), 523-530.

Heredia, F. J., Francia-Aricha, E. M., Rivas-Gonzalo, J. C., Vicario, I. M., \& Santos-Buelga, C. (1998). Chromatic characterization of anthocyanins from red grapes-I. pH effect. Food Chemistry, 4, 491-498.

Hutchings, J. B. (1994). Food colour and appearance. London: Blackie.

Lamuela-Raventós, R. M., \& Waterhouse, A. L. (1994). A direct HPLC separation of wine phenolics. American Journal of Enology and Viticulture, 45, 1-5.

Lapidot, T., Harel, S., Akiri, B., Granit, R., \& Kanner, J. (1999). pHdependent forms of red wine anthocyanins as antioxidants. Journal of Agricultural and Food Chemistry, 47, 67-70.

Little, A. C. (1975). Off on a tangent. Journal of Food Science, 40, $410-411$.

Matsumoto, H., Nakamura, Y., Hirayama, M., Yoshiki, Y., \& Okubo, K. (2002). Antioxidant activity of black currant anthocyanin aglycons and their glycosides measured by chemiluminescence in a neutral $\mathrm{pH}$ region and in human plasma. Journal of Agricultural and Food Chemistry, 50, 5034-5037.

McGuire, R. G. (1992). Reporting of objective colour measurements. HortScience, 27(12), 1254-1255. 
Rodríguez-Saona, L. E., Giusti, M. M., \& Wrolstad, R. E. (1999). Colour and pigment stability of red radish and red-fleshed potato anthocyanins in juice model systems. Journal of Food Science, 64(3), 451-456. Wang, H., Nair, M. G., Strasburg, G. M., Chang, Y. C., Booren, A. M., Gray, J. I., et al. (1999). Antioxidant and anti-inflammatory activities of anthocyanins and their aglycon, cyanidin, from tart cherries. Journal of Natural Products, 62, 294-296.

Voss, D. H. (1992). Relating colourimeter measurement of plant colour to the royal horticultural society colour chart. HortScience, 27(12), 1256-1260. 